Research Paper

\title{
Influence of Wing Loading on the Selection of Prey Size in the Indian False Vampire Bat Megaderma lyra
}

\author{
P KALIRAJ (D) , P VIMAL (D) and G MARIMUTHU* \\ Department of Animal Behaviour and Physiology, School of Biological Sciences, Madurai Kamaraj \\ University, Madurai 625 021, India
}

(Received on 08 July 2015; Revised on 28 January 2016; Accepted on 10 February 2016)

\begin{abstract}
We studied wing loading of adult male $(n=6)$ and female $(n=5)$ of the Indian false vampire bat Megaderma lyra under seminatural conditions in an outdoor enclosure. Before releasing the bats into the enclosure, we measured their body mass, forearm length, wing area and wingspan. They were fed with frogs of four different categories of body lengths such as $\mathrm{A}=$ $3.0-3.5, \mathrm{~B}=4.0-4.5, \mathrm{C}=5.0-5.5$ and $\mathrm{D}=6.0-6.5 \mathrm{~cm}$. Bats were able to capture frogs $\mathrm{A}-\mathrm{C}$ and carry them to roosts, that were at a height of $260 \mathrm{~cm}$ from the ground. However, when they captured frogs of the size D, most of the times they dropped the latter either after reaching the roost or even while carrying them. Alternatively, the bats carried the frogs (size D) but landed at a place $(n=30)$ closer to the ground and began consuming the prey. In general, greater the size of frogs, higher the wing loading of bats.
\end{abstract}

Keywords: Bats; Megaderma lyra; Wing Loading; Frogs; Wing Morphology; Prey Size

\section{Introduction}

Bats are unique among mammals in their capacity for powered flight. Flight is a form of locomotion that enables bats foraging over large areas and in areas of difficult access, and also allows migration over longer distances (Norberg, 1994). Wing loading is highly correlated with body mass and wing dimensions are used to predict foraging habits (Norberg, 1990; Norberg and Rayner, 1987). Bats' wing can be divided into different morphological sectors such as propatagium, plagiopatagium, dactylopatagium and uropatagium and each part has different roles in flight. Dactylopatagium is related to power generation and propulsion of the bat in air, and plagiopatagium is related to the maintenance of this generated force. On the other hand, propatagium and uropatagium are related to the adjustment of flight and in some insectivorous bats, and uropatagium is also used for capturing insects during flight (Altringham, 1996). Flight performance is critically dependent on body mass and on the ratio between body mass and wing area is commonly known as wing loading. For instance, the minimum theoretical flight speed is directly proportional to the square root of wing loading; the minimum theoretical radius of a banked turn is directly proportional to wing loading; and when the aspect ratio and wingspan are constant (for example in a fully grown individual), then the minimum theoretical power requirement for flight is proportional to body mass (Norberg, 1987). When an animal carries a load, one aspect of flight performance that might be comprised is climbing flight, which may be defined as the process of increasing the potential energy of center of mass while flying at low speeds. This type of flight is required to take-off from the ground and to navigate in highly cluttered environments, such as dense foliage or inside the caves. In this study, we observed the wing loading of adult male and female Indian false vampire bats Megaderma lyra, when flying with and without frogs (prey) in their mouths.

\section{Materials and Methods}

The study was conducted in an outdoor enclosure at the botanical garden of the MKU campus. Six male

*Author for Correspondence: E-mail: emailboxgm@gmail.com 
and five female adult individuals of Megaderma lyra were captured by using a nylon mosquito net, when they returned from foraging area to a cave situated in a hilly complex at the village known as Pannian, about $10 \mathrm{~km}$ away from the MKU campus towards northwest. The captured bats were released into the outdoor enclosure $(7.5 \times 3.4 \times 3.5 \mathrm{~m})$ that consisted of an artificial pond $(4.2 \times 2.3 \times 0.6 \mathrm{~m})$, and a dark roost chamber. Before releasing the bats, their body weight was measured by using an Avinet spring scale to the accuracy of $0.5 \mathrm{~g}$. The lengths of their forearm were measured by using vernier calipers to the accuracy of $0.1 \mathrm{~mm}$. Afterwards, each bat was placed on a graph sheet with its wings fully stretched. The outer margin/s of the wing membranes including the head and tail regions were traced. Measurements were made on wing area and wingspan. The wing loading was calculated by using the formula body weight $\times \mathrm{g} /$ wing area (g-indicates gravitational acceleration $9.81 \mathrm{~m}^{-2}$ ) (Norberg and Rayner, 1987).

Frogs (Rana tigerina) were captured in the natural ponds and released into the pond at the outdoor enclosure after measuring their body weight and body length (snout to vent). The frogs were divided into four categories, A, B, C and D having body lengths of 3.0-3.5, 4.0-4.5, 5.0-5.5 and 6.0-6.5 cm, respectively. Observations were made daily four times a day $18.45 \mathrm{~h}, 21.00 \mathrm{~h}, 24.00 \mathrm{~h}$ and $02.00 \mathrm{~h}$. During each observation, a frog was placed on the sandy floor, covered with a beaker and allowed to settle. The beaker was gently removed soon after the frog settled on the floor. If a frog did not jump within a period of $10 \mathrm{~min}$, the observation was terminated. During each observation, frogs were chosen randomly among the four categories. At the end of each experiment, the bats were released at the site of capture.

\section{Results}

The body length and body weight of the four categories of frogs and the wing loading of bats without and with carrying the frogs are provided in Table 1. As soon as a frog jumped the bats flew down, pounced on the frog, captured the scrape of the neck with the mouth and flew away. After reaching a roost ' $\mathrm{S} 1$ ' or 'S2' (Fig. 1), the bats began to consume the frog by chewing. The bats never captured frogs that didn't jump. The number of jumps made by each frog before captures and the time taken by a bat to consume the
Table 1: Mean values of frog body length, body weight and wing loading of adult Male $(n=6)$ and female $(n=5)$ bats while carrying frogs

\begin{tabular}{lccc}
\hline $\begin{array}{l}\text { Body length } \\
\text { of frog }(\mathrm{cm}) \& \\
\text { categorization }\end{array}$ & $\begin{array}{c}\text { Body weight of } \\
\text { frog }(\mathrm{kg})\end{array}$ & \multicolumn{2}{c}{$\begin{array}{c}\text { Wing loading of bats } \\
\text { with frog }\left(\mathrm{Nm}^{-2}\right)\end{array}$} \\
\cline { 3 - 4 } & & Male $^{\mathrm{a}}$ & Female $^{\mathrm{b}}$ \\
\hline $3.0-3.5(\mathrm{~A})$ & $0.004 \pm 0.0(109)$ & $13.51 \pm 0.2$ & $12.83 \pm 0.1$ \\
$4.0-4.5(\mathrm{~B})$ & $0.007 \pm 0.0(305)$ & $14.38 \pm 0.1$ & $13.74 \pm 0.1$ \\
$5.0-5.5(\mathrm{C})$ & $0.011 \pm 0.0(151)$ & $15.77 \pm 0.2$ & $15.11 \pm 0.2$ \\
$6.0-6.5(\mathrm{D})$ & $0.018 \pm 0.0(49)$ & $17.28 \pm 0.2$ & $17.12 \pm 0.2$ \\
\hline
\end{tabular}

${ }^{a}$ Wing loading of male bats without frogs: $12.4 \pm 0.62 \mathrm{Nm}^{-2}$

${ }^{b}$ Wing loading of female bats without frogs: $11.7 \pm 0.82 \mathrm{Nm}^{-2}$

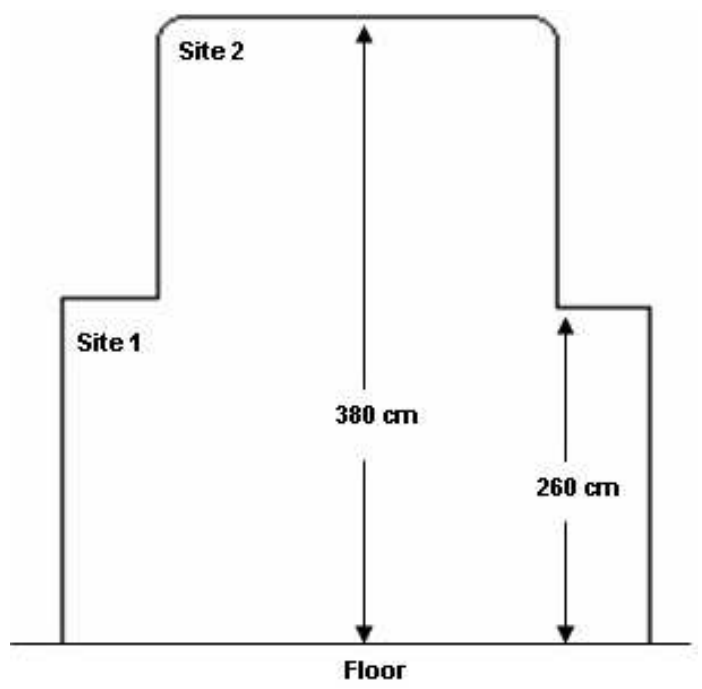

Fig. 1: Diagrammatic view of the feeding area of bats at the outdoor enclosure (vertical section)

entire frog were noted. Bats were able to capture and carry the frogs A-C to the roost. Whereas, when they captured whilst carrying the frogs $\mathrm{D}$, most of the times the bats dropped frogs before reaching the roost. Numbers of male and female bats that dropped when carrying frogs (D) were 13 and 9, respectively. However, in a few occasions $(n=30)$, the bats settled on a place within $15 \mathrm{~cm}$ from the floor and began to consume frog $\mathrm{D}$. The duration of consumption of entire frogs increased with increase in body length of frogs (Fig. 2). Similarly, the number of jumps made by frogs decreased with the increase in their body lengths, before captured by the bats (Fig. 3).

Among the male bats, comparisons of wing loading with and without carrying frogs $\mathrm{A}(\mathrm{t}=-1.36$, $\mathrm{P}=0.20, \mathrm{df}=10)$ and $\mathrm{B}(\mathrm{t}=-2.25, \mathrm{P}=0.05, \mathrm{df}=10)$ 


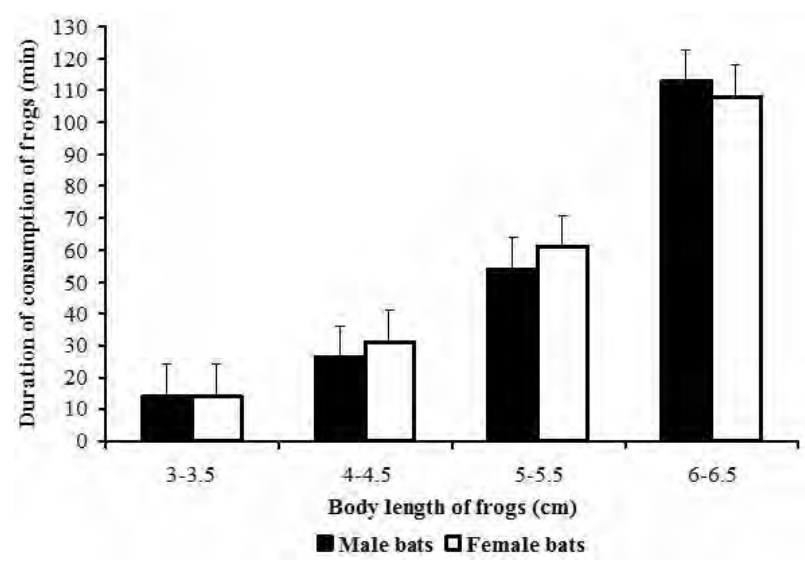

Fig. 2: Body length of frog and duration of consumption by adult bats $\left(\mathrm{n}=6 \delta^{\Uparrow} \delta^{\lambda} ; \mathrm{n}=5\right.$ 우우 $M$. lyra). Frog categories:

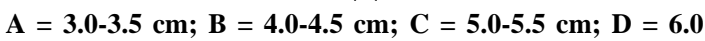
$=6.5 \mathrm{~cm})$. Data are given as mean $\pm \mathrm{SE}$

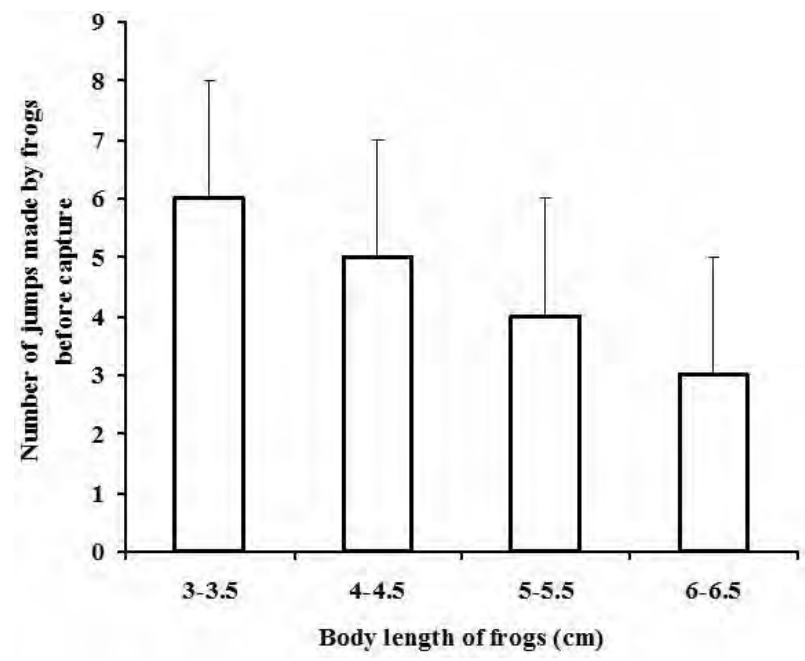

Fig. 3: Number of jumps made by frogs before captured by bats. Frog categories: $A=3.0-3.5 \mathrm{~cm} ; B=4.0-4.5 \mathrm{~cm}$; $C$ $=5.0-5.5 \mathrm{~cm} ; \mathrm{D}=6.0=6.5 \mathrm{~cm})$. Data are given as mean $\pm \mathrm{SE}$

were not showing significant difference. Whereas, significant differences were found on such comparisons with frogs $\mathrm{C}(\mathrm{t}=-3.72, \mathrm{P}=0.004, \mathrm{df}=$ $10)$ and $D(t=-3.97, P<0.001, d f=10)$. Similarly, comparison of wing loading of female bats with and without frogs in their mouths showed no significant difference for both frogs $\mathrm{A}(\mathrm{t}=-0.97, \mathrm{P}=0.36, \mathrm{df}=$ 8) and $\mathrm{B}(\mathrm{t}=-1.73, \mathrm{P}=0.12, \mathrm{df}=8)$. On the other hand, there were significant differences in the wing loading with frog $\mathrm{C}(\mathrm{t}=2.1, \mathrm{P}=0.02, \mathrm{df}=8)$ and $\mathrm{D}(\mathrm{t}$ $=-3.97, \mathrm{P}=0.004$, $\mathrm{df}=8$ ).

\section{Discussion}

Wing loading is one of the important parameters that explain the flight characteristics of flying animals like bats (Iriarte-Díaz et al., 2012; Riskin et al., 2010). In the present study the wing loading of bats increases with increase in the body weight of frogs. Although, the prey size is larger, the bats have to carry them to a roost for consumption. In this context, the optimal prey size is essential for the bat to carry it to reach the roost. Usually, the larger prey items are not always optimal for a predator, because they require more handling time than the smaller prey (Krebs, 1978). The intermediate sized prey may give optimal reward as they provide better balance of capture/handling time for gaining energy (Davies, 1977). Wing loading of female Antrozous pallidus was higher than a male that is due to sexual dimorphism and pre-hibernatory deposition of fat (Davis, 1969). Another study on free ranging bats (Kalcounis and Brigham, 1995) indicated the effect of change in mass of flight by adding weight to simulate natural fluctuations in body mass. Thus, increase in body mass decreases flight efficiency. The dropping of the largest frogs (D) by M. lyra while carrying them clearly demonstrates that heavier prey apply constrain on the flight. Because the female has relatively lower wing loading, they have the capacity to exhibit increased lift. Moreover, during breeding season, the pregnant and lactating females have to carry such prey along with the weight of the fetus and infants. Hence, lower wing loading is an advantage for females. The optimal prey size for M. lyra in our study appears to be body lengths of $4.0-4.5 \mathrm{~cm}$, because it required an optimal time of $30 \mathrm{~min}$ to consume the entire frogs. It is clear though, that the number of jumps needed was relatively less to capture the larger frogs. This may be due to the movement of larger frogs on dry sandy floor create relatively more intensive rustling sound when compared to the smaller frogs(Marimuthu et al., 2002).

\section{Acknowledgements}

We thank the Department of Science and Technology, Government of India through research grant to GM. P Kaliraj thank UGC Meritorious under Basic Scientific Research Fellowship to him. GM is supported by INSA with a Senior Scientist position. There is no conflict of interest on this study with any scientist. 


\section{References}

Altringham J D (1996) Bats-biology and behaviour, Oxford University Press

Davies N B (1977) Prey selection and the search strategy of the spotted flycatcher Muscicapa striata: A field study on optimal foraging Anim Behav 25 1016-1023

Davis R (1969) Wing loading in pallid bats J Mammal 50140-144

Iriarte-Díaz J, Riskin D K, Breuer K S and Swartz S M (2012) Kinematic plasticity during flight in fruit bats: individual variability in response to loading PLOS ONE 7 e36665

Kalcounis M C and Brigham R M (1995) Intraspecific variation in wing loading affects habitat use by little brown bats (Myotis lucifugus) Can J Zool 73 89-95

Krebs J R (1978) Optimal foraging: decision rules for predators. In: Behavioural ecology an evolutionary approach (Eds: Krebs J R and Davies N B) pp 2-63, Blackwell Publication, Oxford

Marimuthu G, Emmanuvel Rajan K, Sripathi K, Parsons S and Jones G (2002) Effects of different surfaces on the perception of prey-generated noise by the Indian false vampire bat Megaderma lyra Acta Chiropterol 4 25-32

Norberg U M (1987) Wing form and flight mode in bats. In: Recent Advances in the Study of Bats (Eds: Fenton M B and Racey P A) pp 43-56, Cambridge University Press, Cambridge

Norberg U M (1990) Vertebrate flight: Mechanics, physiology, morphology, ecology and evolution, Springer

Norberg U M (1994) Wing design, flight performance, and habitat use in bats. In: Ecological morphology: Integrative organismal biology (Eds: Wainwright PC and Reilly S M) pp 205-239, University of Chicago Press, Chicago

Norberg U M and Rayner J M V (1987) Ecological morphology and flight in bats (Mammalia: Chiroptera): wing adaptations, flight performance, foraging strategy and echolocation Phil Trans R Soc Lond B Biol Sci 316 335427

Riskin D K, Iriarte-Díaz J, Middleton K M, Breuer K S and Swartz S M (2010) The effect of body size on the wing movements of pteropodid bats, with insights into thrust and lift production J Exp Biol 213 4110-4122. 